\title{
Biosynthesis of thromboxane in patients with systemic sclerosis and Raynaud's phenomenon
}

\author{
I A G REILLY, L ROY, G A FITZGERALD
}

\begin{abstract}
Thromboxane $\mathbf{A}_{2}$, the predominant cyclo-oxygenase product of arachidonic acid in platelets, is a potent vasoconstrictor and platelet agonist. Analysis of urinary metabolites by gas chromatography and mass spectrometry is a specific non-invasive method of measuring the biosynthesis of thromboxane that avoids the problem of platelet activation ex vivo. Excretion of the major urinary thromboxane metabolite, 2,3-dinor-thromboxane $B_{2}$, was significantly increased $(p<0.001)$ in 10 patients (nine women) with systemic sclerosis complicated by Raynaud's phenomenon compared with healthy controls (486 (SD 88) $v 162$ (38) $\mathrm{ng} / \mathrm{g}$ creatinine) and increased further in the patients (to 1007 (212) $\mathrm{ng} / \mathrm{g}$ creatinine) during application of a cold stimulus sufficient to induce digital vasoconstriction. Consistent with an increase in platelet-vascular interactions in vivo, excretion of a prostacyclin metabolite was also significantly increased $(\mathbf{p}<0.005)$ in the patients with systemic sclerosis $(248(39) v 112$ (10) $\mathrm{ng} / \mathrm{g}$ creatinine) and tended to increase further on cooling.

Biosynthesis of thromboxane is increased in patients with systemic sclerosis and may exacerbate digital vasospasm that such patients develop when cold. This observation and the concomitant increase in the formation of prostacyclin provide a rationale for evaluating compounds that prevent the synthesis of thromboxane $A_{2}$ or inhibit its action while preserving the potential homoeostatic role of prostacyclin.
\end{abstract}

\section{Introduction}

Raynaud's phenomenon is characterised by episodic, exaggerated constriction of the small digital arteries and arterioles in response to cold or emotional stress.' Studies of Raynaud's phenomenon

\footnotetext{
Division of Clinical Pharmacology, Vanderbilt University, Nashville, Tennessee 37232, USA

I A G REILLY, MB, MRCP, research fellow

L ROY, MD, research fellow

$G$ A FITZGERALD, MD, FRCPI, associate professor of medicine and pharmacology

Correspondence and requests for reprints to: Dr FitzGerald.
}

associated with systemic sclerosis have shown histological changes of intimal hyperplasia and severe fibrosis in the veins ${ }^{23}$ and an excessive reduction in peripheral blood flow after administration of vasoconstrictors. ${ }^{4}$ Thromboxane $\mathrm{A}_{2}$, the predominant cyclo-oxygenase metabolite formed from arachidonic acid in the platelet, ${ }^{5}$ is a potent vasoconstrictor and platelet agonist. Because of this and the evolving therapeutic regimens designed selectively to inhibit synthesis of thromboxane ${ }^{6}$ or to antagonise its action, ${ }^{7}$ we studied the formation of thromboxane in vivo in patients with systemic sclerosis complicated by Raynaud's phenomenon. We used a specific, sensitive, and non-invasive approach to measure the biosynthesis of thromboxane to see whether it is increased in such patients and whether induction of Raynaud's phenomenon by exposure to cold is associated with a further increase.

\section{Patients and methods}

Ten patients (nine women and one man) with systemic sclerosis (scleroderma) complicated by symptomatic Raynaud's phenomenon participated in the study, which was approved by the Committee for the Protection of Human Subjects at Vanderbilt University Medical Center. Ages ranged from 36 to 60 (mean 45.4 ) years and each patient fulfilled the criteria of the American Rheumatism Association for a diagnosis of systemic sclerosis. ${ }^{8}$ Patients excluded had a clinical history or laboratory evidence (electrocardiogram and routine automated biochemical screen) of ischaemic heart disease or renal impairment (serum creatinine concentration $>133 \mu \mathrm{mol} / \mathrm{l}$ $(>1.5 \mathrm{mg} / 100 \mathrm{ml}))$ or were taking antiplatelet drugs. All patients studied were non-smokers and refrained from taking aspirin for at least two weeks before the study.

The patients and 10 healthy controls matched for age and sex were studied before and after central cooling had been induced with a cooling blanket (Aquamatic-K-thermia, Gorman-Rupp, Bellville, Ohio). Cooling continued for 30 minutes or until Raynaud's phenomenon developed, which was observed in all patients. Care was taken to ensure that the maximum fall in the subject's normal oral temperature did not exceed $3^{\circ} \mathrm{F}$. Blood samples were taken before cooling for measurement of plasma $\beta$ thromboglobulin and platelet factor 4 , serum thromboxane $B_{2}$, and platelet aggregation in response to arachidonic acid. Urine was collected for 24 hours before the study, followed by a second collection corresponding to the time of cooling, for measurement of the major urinary metabolites of thromboxane, 2,3dinor-thromboxane $\mathrm{B}_{2}$ and prostacyclin, 2,3-dinor-6-keto-prostaglandin $\mathrm{F}_{\mathrm{lk}}$.

Biochemical analyses-2,3-Dinor-thromboxane $\mathrm{B}_{2}$ and 2,3-dinor-6-ketoprostaglandin $\mathrm{F}_{\mathrm{l}, \mathrm{t}}$ were measured by stable isotope dilution assays using gas chromatography and mass spectrometry in the negative ion-chemical 
ionisation mode..$^{10}$ Serum thromboxane $\mathbf{B}_{2}$ generation in vitro was measured by radioimmunoassay using the method of Patrono et al. ${ }^{11}$

Platelet function tests-Platelet aggregation was studied using a light transmission method in a Payton dual channel aggregometer. ${ }^{12}$ The threshold aggregating concentration for arachidonic acid was determined (defined as the minimum concentration of arachidonic acid producing greater than $70 \%$ increase in light transmission). The platelet $\alpha$ granule constituents were measured by radioimmunoassay (Amersham and Abbott Laboratories)

Statistical analyses were performed using a non-parametric method (the Wilcoxon rank sum test) to avoid making assumptions about the distribution of the variables.

\section{Results}

Basal excretion of 2,3-dinor-thromboxane $B_{2}$ was significantly increased in the patients with systemic sclerosis and Raynaud's phenomenon $(\mathrm{p}<0.001)$ compared with the healthy controls (486 (SD 88) $v 162(38) \mathrm{ng} / \mathrm{g}$ creatinine). Basal excretion of 2,3-dinor-6-keto-prostaglandin $F_{k \text { ce }}$ was also more than double in the patients compared with the controls (248 (39) 112 (10) $\mathrm{ng} / \mathrm{g}$ creatinine; $\mathrm{p}<0.005)$. Both plasma $\beta$ thromboglobulin concentration $(57(16) \quad v 14(2) \quad \mu \mathrm{g} / \mathrm{l} ; \mathrm{p}<0.005)$ and platelet factor concentration $(43(14) v 6(1) \mu \mathrm{g} / \mathrm{l} ; \mathrm{p}<0.005)$ were significantly higher in the patients. The threshold concentration for platelet aggregation in response to arachidonic acid was also significantly lower $(\mathrm{p}<0.005)$ in the patients $(0 \cdot 16$ $(0.04) \mathrm{mmol} / \mathrm{l})$ compared with the healthy subjects $(0.38(0.06) \mathrm{mmol} / \mathrm{l})$. The ability of platelets to generate thromboxane $\mathrm{A}_{2}$ as measured by serum thromboxane $B_{2}$ generation was normal in all of the patients (301 (72) $v 276$ (71) $\mu \mathrm{g} / \mathrm{l}$ ) and confirmed that patients had avoided taking aspirin.

There was no significant effect of cooling on excretion of either of the metabolites in the controls (table). Typical clinical signs of Raynaud's phenomenon developed in the digits of all the patients with systemic sclerosis during cooling. There was a concomitant, significant increase in excretion of 2,3-dinor-thromboxane $B_{2}$ from 416 (80) to 1007 (212) ng/g creatinine $(\mathrm{p}<0.05)$ during cooling (table) and a tendency for excretion of 2,3-dinor-6-keto-prostaglandin $F_{\mathrm{lc}}$ to increase during cooling, though this did not attain significance. study. Excretion of 2,3-dinor-thromboxane $B_{2}$, the major metabolite of thromboxane in urine, ${ }^{17}$ is a sensitive, specific, and non- 므 invasive index of endogenous biosynthesis of thromboxane. ${ }^{18} ?$

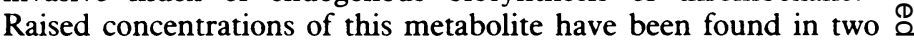
additional models of platelet activation in vivo-namely, severe $c$ peripheral vascular disease ${ }^{19}$ and unstable angina. ${ }^{20}$ In the present $\widehat{\widehat{\Omega}}$ study further evidence suggesting platelet activation in vivo was provided both by the concomitant increase in plasma concentrations of platelet granule constituents and by the increase in endogenous $\infty$ formation of prostacyclin. Excretion of 2,3-dinor-6-keto-prosta- $\mathrm{Q}$ glandin $F_{1 \alpha}$ is a non-invasive index of biosynthesis of prostacyclin that has been used to predict accurately the circulating concentrations of prostacyclin ${ }^{21}$ and reflect alterations in vascular biosynthesis of this eicosanoid. ${ }^{22}$ We previously showed considerable enhancement of biosynthesis of prostacyclin in patients with advanced on peripheral vascular disease and platelet activation in vivo ${ }^{1923}$ and a $\vec{\nabla}$ less pronounced increase in chronic cigarette smokers, who exhibited a correspondingly smaller increment in excretion of 2,3dinor-thromboxane $\mathrm{B}_{2}{ }^{24}$ Thus local formation of prostacyclin at sites of platelet-vascular interactions may have a homoeostatic role in the setting of platelet activation in vivo.

We also found increased sensitivity of platelets to aggregation induced by arachidonic acid ex vivo in patients with systemic sclerosis. Additionally, plasma concentrations of the platelet granule constituents $\beta$ thromboglobulin and platelet factor 4 , were $N$ considerably raised in the patients. This may reflect the presence of $\mathcal{N}$ platelet activation in vivo or increased sensitivity of platelets obtained from patients with systemic sclerosis to activation ex vivo. The clearance of platelet factor 4 from plasma is extremely rapid $\underset{v}{ }$ whereas the plasma half life of $\beta$ thromboglobulin is more pro- 0 longed (about 100 minutes). Measurement of both platelet proteins in the same sample may, therefore, permit distinction between platelet activation in vivo and ex vivo. ${ }^{25}$ The coincidental increase in platelet factor 4 suggests that the appreciable increase in $\beta$

Mean (SD) excretions of 2,3-dinor-thromboxane $B_{2}$ and 2,3-dinor-6-keto-prostaglandin $F_{I a}(n g / g$ creatinine) in patients with systemic sclerosis and healthy controls before and during cooling

\begin{tabular}{lccccccc}
\hline & \multicolumn{3}{c}{ Patients with systemic sclerosis } & & \multicolumn{2}{c}{ Healthy controls } \\
\cline { 2 - 3 } & Before cooling & During cooling & Significance & & Before cooling & During cooling & Significance \\
\hline 2,3-Dinor-thromboxane $B_{2}$ & $416(80)$ & $1007(212)$ & p $<0.05$ & & $162(38)$ & $284(109)$ & NS \\
2,3-Dinor-6-keto-prostaglandin $F_{l u}$ & $248(39)$ & $362(81)$ & NS & & $112(10)$ & $139(18)$ & NS \\
\hline
\end{tabular}

\section{Discussion}

Endogenous biosynthesis of thromboxane $\mathrm{A}_{2}$, a potent vasoconstrictor and platelet agonist, is significantly increased in patients with systemic sclerosis complicated by Raynaud's phenomenon. Moreover, a further increase in biosynthesis occurred when the syndrome was precipitated by exposure to cold. Such an observation is consistent with the presence of platelet activation in vivo and suggests that in patients with systemic sclerosis platelets are activated on application of a cold stimulus sufficient to induce Raynaud's phenomenon.

Previous studies of the biosynthesis of thromboxane in Raynaud's phenomenon have relied on measurement of plasma concentrations of thromboxane $B_{2}{ }^{1314}$ This variable is readily confounded by platelet activation in vitro. Whereas the ability of platelets to form thromboxane $B_{2}$ in serum is $300-400 \mu \mathrm{g} / \mathrm{l}$, concentrations of 100 $200 \mathrm{ng} / \mathrm{l}$ are commonly reported in plasma. ${ }^{13}$ is Thus activation of platelets to less than $0 \cdot 1 \%$ of their capacity would be sufficient to account for these "endogenous" concentrations. That these concentrations indicate in vitro activation or are an analytical artefact, or both, is supported by non-invasive, maximal estimates of endogenous thromboxane $B_{2}$ concentrations in plasma in the range 1-2 $\mathrm{ng} / \mathrm{l}$ derived from urinary metabolite excretion during infusion of thromboxane $\mathrm{B}_{2} .{ }^{16}$ The problems of interpreting such indices of platelet activation in vivo led us to use an alternative approach in this thromboglobulin noted in the patients may have derived, at least in part, from platelet release in vitro. This is not unexpected in view of $\frac{0}{3}$ the greater difficulty in obtaining blood samples free of stasis from such patients. As concentrations of platelet factor 4 were not $ᄋ$ measured in earlier studies, ex vivo artefact may perhaps have $₹$ contributed to the raised concentrations of $\beta$ thromboglobulin 윽

previously reported in patients with systemic sclerosis. ${ }^{26}{ }^{27}$
Clinical trials of drugs that inhibit thromboxane synthase have generally failed to show any appreciable benefit in Raynaud's phenomenon..$^{131428.30}$ These studies are, however, unlikely to have assessed the importance of thromboxane $\mathrm{A}_{2}$ as a mediator in this $\mathrm{N}$ disease. Firstly, studies both in vitro and in vivo have shown that $\omega$ prostaglandin endoperoxide substrate accumulates during inhibition of thromboxane synthase and substitutes for the action $\frac{0}{C}$ of thromboxane $\mathrm{A}_{2},{ }^{31.33}$ thus limiting the clinical efficacy of $\Phi^{\infty}$ thromboxane synthase inhibitors. Secondly, the regimens used in ${ }^{+}$ clinical trials of thromboxane synthase inhibitors incompletely inhibit biosynthesis of thromboxane. ${ }^{19}$ Maximal inhibition of plate- $\frac{\vec{D}}{\mathbb{D}}$ let thromboxane generation is necessary to inhibit platelet activation $\frac{\rho}{\mathbb{\Phi}}$
dependent on thromboxane. ${ }^{34}{ }^{35}$

In conclusion, endogenous formation of thromboxane $\mathrm{A}_{2}$ is $\bar{\sigma}$ enhanced in patients with systemic sclerosis, and precipitation of $\varnothing$ Raynaud's phenomenon by exposure to cold is associated with a을 further increase in biosynthesis of thromboxane. A coincidental

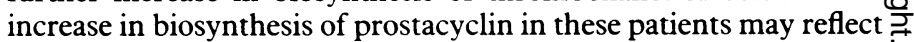


a homoeostatic mechanism whereby the vasospastic and platelet aggregatory actions of thromboxane $\mathrm{A}_{2}$ are attenuated. These results provide a rationale for evaluating treatment that inhibits thromboxane $A_{2}$ while preserving the synthesis of prostacyclin.

This study was supported by a grant (HL 30400) from the National Institutes of Health. LR was supported in part by grants from the Quebec Heart Foundation and the Tennessee Affiliate of the American Heart Association. GAF is an established investigator for the American Heart Association.

\section{References}

1 Freedman RR, Ianni P. The role of cold and emotional stress in Raynaud's disease and scleroderma. Br.Med f 1983:287: 1499-502.

2 Rodnan GP, Myerowitz RL. Justh GO. Morphologic changes in the digital arteries of patients with progressive systemic sclerosis (scleroderma and Ravnaud's phenomenon. Medicine with progressive systemic
Baltimore 1980;59:393-407.

3 Lerov EC. Pathogenesis of scleroderma (svstemic sclerosis . F Invest Dermatol 1982;79:87-9.

4 Halpern A, Kuhn PH, Shaftel HE, et al. Raynaud's disease. Ravnaud's phenomenon and serotonin. Angiology 1960;11:151-67.

5 Hamberg M. Svensson J, Samuelsson B. Thromboxanes: a new group of biologically active compounds derived from prostaglandin endoperoxides. Proc Natl Acad Sci USA 1975;72 2994-8

6 Needleman P. Raz R, Ferrendelli JA, Minkes M. Application of imidazole as a selective inhibito of thromboxane synthetase in human platelets. Proc Nall Acad Sci USA 1977;74:1716-20.

7 Jones RL, Wilson NH, Armstrong RA, Peesapati V, Smith GM. Effects of the thromboxane antagonist EP045 on platelet aggregation. Adv Prostaglandin Thromboxane Leukotriene Res $1983: 11: 345-50$

8 American Rheumatism Association. Preliminary criteria for the classification of systemic sclerosis scleroderma). Arthritis Rheum 1980;23:581-90.

9 Lawson JA, Brash AR, Doran J, FitzGerald GA. Measurement of urinary 2,3-dinor-thromboxane $B_{2}$ and thromboxane $B_{2}$ using bonded phase phenyl boronic acid columns and capillary gas $\mathrm{B}_{2}$ and $\mathrm{B}$ ra $463-70$.

10 FitzGerald GA, Lawson JA, Blair IA, Brash AR. Analvsis of urinary metabolites of thromboxane and prostacyclin by negative ion-chemical ionization gas chromatography-mass spectrometry. Advances in Prostaglandin Thromboxane and Leukotriene Research 1985;15:87-90.

11 Patrono C, Ciabattoni G, Pinca E, et al. Low dose aspirin and inhibition of thromboxane $\mathrm{B}_{2}$ production in healthy subjects. Thromb Res 1980;17:317-27.

12 Born GVR. Aggregation of blood platelets by adenosine diphosphate and its reversal. Nature 1962;194:927-9.

13 Luderer JR, Nicholas GG, Neumyer MM, et al. Dazoxiben, a thromboxane synthetase inhibitor, in Raynaud's phenomenon. Clin Pharmacol Ther 1984;36:105-15.
14 Belch JJF, Cormie J, Newman P, et al. Dazoxiben, a thromboxane synthetase inhibitor, in the treatment of Raynaud's syndrome: a double blind trial. Br f Clin Pharmacol 1983;15:113-6.

15 Hirsh PD, Hillis LD, Campbell WB, Firth BG, Willerson JT. Release of prostaglandins and thromboxane into the coronary circulation in patients with ischemic heart disease. $N \mathrm{Engl}$. Med 1981;304:685-91

16 Patrono C, Ciabattoni G, Pugliese F, Peirucci A, Blair IA, FitzGerald GA. Estimated rate of thromboxane secretion into the circulation of normal man. 7 Clin Invest 1986;77:590-4.

17 Ruberts LJ, Sweetman BJ, Oates JA. Metabolism of thromboxane $\mathbf{B}_{2}$ in man: identification of twenty metabolites. 7 Biol Chem 1981;256:8384-93.

18 FitzGerald GA, Pedersen AK. Patrono C. Analysis of prostacyclin and thromboxane $A_{2}$ biosvnthesis in cardiovascular disease. Circulation 1983;67:1174-7.

19 Reilly IAG, Doran J, Smith B, FizGerald GA. Increased thromboxane biosynthesis in a human model of platelet activation: biochemical and functional consequences of selective inhibition of thromboxane synthase. Circulation (in press

20 Fitzgerald DJ, Roy LR, FitzGerald GA. Enhanced prostacyclin and thromboxane $\mathrm{A}_{2}$ synthesis in ischemic heart disease: non-invasive evidence of sporadic platelet activation in unstable angina. Circulation 1985;72:1688

21 FitzGerald GA. Brash AR, Falardeau P, Oates JA. Estimated rate of prostacyclin secretion into the circulation of normal man. $\mathcal{F}$ Clin Invest 1981;68:1272-5.

22 Rov L, Knapp H, Robertson RM, FitzGerald GA. Endogenous biosvnthesis of prostacyclin during cardiac catheterization and angiography in man. Circulation 1985;71:434-9.

23 FitzGerald GA, Smith B, Pedersen AK, Brash AR. Increased prostacyclin biosynthesis in patients with severe atherosclerosis and platelet activation. N Engl f Med 1984:310:1065-8.

24 Nowak J. Murray JJ, Oates JA, FitzGerald GA. Platelet function and the in vivo formation of thromboxane $\dot{A}_{2}$ and prostacyclin during chronic smoking and withdrawal in man [Abstract]. Thromb Hemost 1985;54:1029.

$25 \mathrm{Kaplan} \mathrm{KL}$. Owen J. Plasma levels of $;$;-thromboglobulin and platelet factor 4 as indices of platele activation in vivo. Blood 1981:47:199-202.

26 Zahavi J, Hamilton WAP, O'Reilly MJG, Levton J, Cotton LT, Kakkar WV. Plasma exchange and platelet function in Raynaud's phenomenon. Thromb Res 1980;19:85-93.

27 Kahaleh MB, Osborn I, Leroy EC. Elevated levels of circulating platelet aggregates and $\beta$ thromboglobulin in scleroderma. Ann Intern Med 1982;96:610-3.

28 Ettinger WH, Wise RR. Schaffhauser D, Wigley FM. Controlled double-blind trial of dazoxiben and nifedipine in the treatment of Raynaud's phenomenon. Am J Med 1984:77:451-6.

Coffman JD, Rasmussen HM. Effect of thromboxane synthetase inhibition in Raynaud's phenomenon. Clin Pharmacol Ther 1984:36:369-73.

30 Jones EW, Hawkev CJ. A thromboxane synthetase inhibitor in Ravnaud's phenomenon Prostaglandins Leukotrienes Med 1983;12:67-71.

31 Bertele V, de Gaetano G. Potentiation by dazoxiben, a thromboxane sunthetase inhibitor, of platelet aggregation inhibitory activity of a thromboxane receptor antagonist and of prostacvclin. Eur 7 Pharmacol 1982:85:331-3.

32 FitzGerald GA. Reilly IAG, Pedersen AK. The biochemical pharmacology of thromboxane svnthase inhibition in man. Circulation 1985:72:1194-201.

33 Fitzgerald DJ, Fragetta JE, Jackson EK. FitzGerald GA. Prostaglandin endoperoxides limit the platelet inhibitory effects of thromboxane svnthase inhibitors in vivo. Clin Res 1985;33:282.

34 Di Minno G, Silver MJ, Murphy S. Monitoring the entry of new platelets into the circulation after ingestion of aspirin. Blood 1983;61:1081-5.

35 FitzGerald GA. Oates JA. Hawiger J, et al. Endogenous biosynthesis of prostacyclin and thromboxane and platelet function during chronic administration of aspirin in man. $7 \mathrm{Clin}$ Invest 1983;71:676-88.

Accepted 6 February 1986

\title{
Screening for intrauterine growth retardation using ratio of mid-arm circumference to occipitofrontal circumference
}

\author{
N J MEADOWS, J TILL, A LEAF, E HUGHES, B JANI, V LARCHER
}

\begin{abstract}
Uncritical application of standard weight percentile charts, derived from white infants, to infants from different ethnic groups may result in an overestimate of the incidence of intrauterine growth retardation in those groups. The ratio of mid-arm circumference to occipitofrontal circumference was studied in 194 babies (49 Asian, 58 black, and 87 white). In contrast with birth weight the ratio did not vary among the ethnic groups; it was also independent of sex. In a prospective study of
\end{abstract}

Department of Child Health, Salvation Army, Mothers' Hospital, London E5 N J MEADOWS, MB, MRCP, lecturer

J TILL, MB, BSC, senior house officer

A LEAF, MB, MRCP, senior house officer

E HUGHES, $M B, M R C P$, senior house officer

B JANI, MB, DCH, senior house officer

V LARCHER, MB, MRCP, consultant paediatrician

Correspondence to: Dr N J Meadows, Queen Elizabeth Hospital for Children, London E2 8PS
64 neonates whose weight was below the 10th percentile on standard charts the ratio of mid-arm circumference to occipitofrontal circumference was a more accurate predictor than weight of those infants who would develop symptoms associated with intrauterine growth retardation.

The ratio of mid-arm circumference to occipitofrontal circumference therefore provides a simple, accurate, and cheap way of assessing intrauterine growth retardation in areas with a large multiethnic population, where birth weight varies greatly.

\section{Introduction}

The mean birth weight of white infants differs from that of infants born to mothers from other ethnic groups, especially Asian. ${ }^{1-3}$ Because established percentile charts relate to white infants, the criterion of weight alone cannot be used to identify accurately intrauterine growth retardation in infants from other ethnic groups. We measured the ratio of mid-arm circumference to occipitofrontal circumference in normal full term babies from different ethnic 